\title{
Mujeres Sefardies Lectoras y Escritorias, Siglos XIX-XXI
}

Paloma Díaz Mas-Elisa Martin Ortega (eds), Ed. Iberoamericana, 2016,384 pp.

Ana María Tapia-Adler amtuch@u.uchile.cl

La presente obra consta de una introducción y tres partes. La primera parte: Mujeres y literatura: de la cultura oral a la trasmisión escrita (pp 57 -176), La segunda parte: Mujeres sefardíes escritoras s.XIX al XXI (178-335), La tercera y última parte: Un texto inédito de Laura "Bohoreta" (pp 338-364), El libro incluye, además, un índice de autores y obras citadas (pp 365-376) y un acápite sobre los autores del libro (pp 377-384)

La introducción de corte histórico rescata la participación de las mujeres sefaradíes en las letras $\mathrm{y}$, en ella, las editoras del mismo presentan una breve pero contundente reseña histórica de los judíos, principalmente de los Balcanes y el Imperio turco (pp 9-43), donde hablan de educación, sociedad, y del rol que les cupo a las mujeres en sociedades abiertamente patriarcales en donde su actividad estaba constreñida al ámbito de lo privado en contrate con el papel de los varones que participaban en el área pública. Y enuncian con claridad los nuevos aires que, con el tiempo y el acceso a la educación, vivieron las mujeres sefardíes.

En La primera parte: Mujeres y literatura: de la cultura oral a la trasmisión escrita se encuentran seis trabajos:

Tamar Alexander: “La madre tapa la korkova de su ija”. La identidad femenina i el diskurso entre mujeres en la dokumentacion de refranes en ladino, (p.57-69) su autora señala expresamente el objetivo del mismo, basado en refranes que "anoti en djudeoespanyol de la boca de mi madre, Shoshana Aedo" de los que ella escogió 30 refranes en base a las diferentes identidades que compartía con su madre: "mi madre aparesia enfrente de mi komo madre, komo mujer, komo entrevistada; y en funksiones 
komplementarias komo ija, sbhuegra o kos huegra. Las identidadeskomunes entremim madre $i$ yo eran:la de sekso feminino, la apertenensia a la misma famiya $i$ el atadijo maternal...

Teresa Madrid Alvarez-Pier y Paloma DIaz Mas: “Todo era muevo a su vista”. La imagen de las mujeres en manuales escolares sefardies a principios del siglo XX. (pp 71-93).

El objetivo del artículo es analizar cómo se trata la imagen de las mujeres en varios manuales escolares publicados en judeoespañol aljamiados en Salonica y Estambul entre 1903 y 1931. Ello porque los textos escolares transmiten valores, modelos e incluso estereotipos. Los manuales no solo pretenden la enseñanza de la lectoescritura sino, además, son un espacio privilegiado a la hora de atender a los cambios producidos en su sociedad...

Katia Šmid. Yor'e de’a (Jerusalén, 1884), una obra rabínica judeoespañola para mujeres. (pp 95-112). Esta obra está referida, en gran parte, a varios temas relacionados con la mujer judía tradicional. El autor de esta monumental obra, el rabino sefardí Eli'ézer Sem tob Papo confirma la existencia de mujeres que podían leer: $Y$ bien-aventuradas las mujeres que saben meldar (leer) en ladino (Papo 1884:5ª).El contenido de esta obra contiene indicaciones y comentarios acera del cumplimiento de sus preceptos y obligaciones. Las autoras señalan en su conclusión que el contenido de la obra estudiada es variado y que los capítulos analizados son los que mejor describen a la mujer judía sefardí.

Tina Rivlin El libro las madres judías de la época bíblica y su autor, Zemaj Rabiner., Se trata de un libro de ética escrito en judeoespañol escrito por el Rabino Zemaj Rabiner. Trata de 51 mujeres bíblicas y está dirigido a las mujeres sefardíes de Bulgaria y de la diáspora sefardí. Referente al autor, dice que es lituano y que vivió entre los años 18621936. Su trabajo entre los sefardíes de Bulgaria y otros lugares fue especialmente extenso y diverso [...] escribió libro morales en judeoespañol, pronunció sermones los sábados y festivos en las sinagogas y en diversos congresos, y también escribió en la prensa judeoespañola (p.120) 
El artículo es fruto de la tesis doctoral de la autora en donde por primera vez el libro en cuestión es analizado acorde a su género y temas y comparado con libros de ética judeoespañoles, lo que hace de esta tesis original.

María Sánchez-Pérez: Dos calas en la relación entre mujeres y prensa periodica sefardí: Ilustra guerta de istoria (viena, 1880-1882) y Yerushalayim (Jerusalen, 1909). En la introducción la autora se refiere al rol de las mujeres en las comunidades judías y sefardíes y su evolución. De estar confinadas al ámbito de lo privado, sin embargo, gracias al acceso de estudio, principalmente en las escuelas de la Alliance Israélite Universelle permitió el proceso de cambios y a su visibilidad en la sociedad y fuera del ámbito doméstico (p-129) y en ello tuvo mucho que ver la prensa en donde comenzaron a aparecer secciones, artículos, noticias, etc., destinadas al público femenino (p130). Como el titulo lo señala, la autora se referirá a dos periódicos que son representativos de sus épocas. Ilustra Guerta de Istoria, publicado en Viena entre 1880-1882 y del cual fueron publicados 33 números, y Yerushalayim, formaba parte del periódico El Liberal publicado justamente en esa ciudad en 1909, del cual se conocen 13 números,. A decir de la autora... una sección del periódico que estaba pensada para que la leyeran tanto hombres como mujeres parecía ya en el primer nuero de Yerushalayim. Se titulaba "L Edukasion de nuestros ijos...

Entre las conclusiones se señala que el contenido de ambos periódicos eran muy similares [...] a primera vista así podría parecerlo: cuentos, facecias, anécdotas, etc., pero ello no es así ya que en su artículo insiste en que parece que las intenciones de unos editores y otros difieren bastante, en buena medida porque los entornos en los que publican ambos periódicos son también muy distintos (p143)

Ivette Bürki y Aitor García Moreno: MUJER Y PUBLICIDAD.

Los autores, a través de una treintena de ejemplo estudiados concluyen que la imagen femenina se utiliza para captar l atención del lector y [...] la mujer es tenida muyen cuenta por los publicistas del momento como consumidora y usuaria (p.172) pero que no están [...] en condiciones de asegurar la existencia real de mujeres lectoras de publicidad, aunque si piensan que las hubo (p.173) 


\section{Parte Mujeres sefardíes escritoras (Siglos XIX al XXI)}

Gila Hadar. La luz de la Shjina i un espirito muevo ke nasió en el korasón de Reyna Cohen, una mistikana judia en el empesijo del siglo 20.

Escrito en judezmo, señala que se han escrito varios artículos sobre escritoras sefardíes pero que hay obras escondidas y otras que fueron quemados en los fuegos grandes de Salonika $i$ otras sivdades del Imperio Otomano i durante la Segunda Gerra (p. 180).

La autora señala que se centrará en una de las obras que corresponde a la autobiografía de Reyna Kohen que escribió tres libros y artículos políticos sovre diáspora i regmision, mesianismo i renasimiento nacional.(p. 180). Nos relata acerca de la educación de las mujeres sefardíes, incluyendo aquella que recibieron en la escuela protestante y la influencia en la escritura de Reyna Cohen, como habría recibido la Shjiná, entre otros temas.

Elena Romero Mlle. Elisa: una periodista sefardí colaboradora del periódico de Salónica “La época” a principios del siglo xxi.

El artículo se inicia con un análisis de materiales encontrados en el diario La Época sobre el personaje que es el foco de su artículo en el que ella describe a Mlle Elisa y se refiere a los artículos escritos por ella. La autora concluye que su interés radicó en destacar la variedad de temas abordados por nuestra periodista, que no parece encasillada en determinados asuntos. (p.205)

Susy Gruss, La poetisa Esther Morguez Algranti de Esmirna y su poemario 9 Eyluil.

Este articulo tiene por finalidad presentar el Poemario 9 Eylül, publicado en Estambul en 1975y examinar la relación de la escritora con la tradición judía. Los poemas comprenden diversos tópicos, los que meditan sobre símbolos y las prácticas del judaísmo, elegías sobre el tema del Holocausto, odas a personalidades y acontecimientos destacados y poemas de carácter lirico nostálgico, deteniéndose en cada uno de los tópicos ilustrándolos con 
poemas. La autor concluye su artículo señalando que las poesías del poemario 9 Eylül son a veces eclécticas, otras enigmáticas a menudo pesimistas (p. 220). Sin embargo, termina señalando que el matiz conservador de sus argumentos la excluye de la categoría de literatura femenista clásica. (p. 220)

Želkjo Jovanovic. Gina Camhy: una primera aproximación a la vida y obra de la autora sefardí de Bosnia. El objetivo de este artículo es poner en contexto histórico, geográfico y cultural, ofreciendo de este modo al lector una visión panorámica del tipo de literatura que cultivó esta escritora sefardí de Bosnia.(p 225). El autor concluye señalando que la obra de esta escritora es un valioso testimonio de la comunidad sefardí de Bosnia, pues la autora subraya todas las particularidades que caracterizaban a esta comunidad...(p. 237)

Krinka Vidakovic-Petrov, Jamila Andjela Kolonomos: de las memorias al libro conmemorativo.

Luego de una corta presentación de esta escritora judía-romaniota, se continúa narrando acerca de las obras publicadas, en especial la de Monastir sin Djudios, escrito en primera instancia en djudeoespañol y posteriormente en inglés. Para quien escribe el artículo la importancia de esta escritos es importante porque se trata de uno de los pocos relatos de primera mano sobre el Holocausto en Macedonia, es un ejemplo único de la escritura e mujeres sefardies en Macedonia, capta la memoria colectiva de una comunidad perdida, sigue los hechos objetivos, pero también trata de buscar lo subjetivo, profundamente emocional y los aspectos personales de la experiencia individual y porque algunos fragmentos, especialmente los que expresan experiencias personales se articulan como un texto literario (p.252)

Jelena FIlipovic/Ivana Vucina-Simovic. La construcción de la identidad de género y de la identidad sefardí en las novelas autobiográficas de Rosa Nissán y Gordana Kuic.

Las autoras del articulo han decidido escribir acerca de estas dos escritoras por considerar que comparten ciertos elementos biográficos: son sefardíes que buscan mantener tradiciones y costumbres, nacieron en época de la II Guerra Mundial y la publicación de sus 
novelas son casi idénticas (p263) y ambas muestran una clara intención de construir sus propias identidades de mujer y sefardí ante unas circunstancias históricas, sociales y políticas complejas (p 263-4). En el contexto histórico social se escribe acerca de la mujer sefardí en México y en los Balcanes. En las conclusiones se congratulan haber cumplido con su objetivo de poner de relieve un dueto de voces femeninas que descubren trozos de sus historias privadas pero también públicas, comunitarias, en sus obras autobiográficas (p 273)

Michael Studemund-Halevy. Palabras para el pasado. Gracia Albuhayre, una poetisa de Karnobat.

EL autor señala que una característica las mujeres poetas es que escriban en judezmo, una lengua en peligro en Bulgaria, por varias razones, entre las que enumera razones literarias, poéticas y autobiográficas, como una forma de que su identidad judía fluya naturalmente en sus obras (p 278). En Bulgaria hay una gran cantidad de escritoras, poetisas aficionada, escritoras o periodistas que hicieron culminantes contribuciones a la creación de poesía sefardita porque otros géneros no se cultivan (283)

Agnieszka August-Zarebska. La figura de la madre en la poesía de Margalit Matitiahu.

El objetivo del autor de este artículo es mostrar las formas de representación de la figura de la madre en los poemas escogidos de Margalit Matitithu, así como determinar que funciones cumplen dichas representaciones en su obra ( $\mathrm{p}$ 316), cosa que la poetisa hace principal aunque no exclusivamente en judezmo lengua a la que anhelaba mantenerla viva $y$ la intención de recordar a sus mayores y rendir homenaje a su larga y rica tradición cultural (p.303)

Pilar Romeu Ferré. Aproximación a las memorias de mujeres sefardíes del norte de África.

Este artículo tiene como objetivo analizar en una primera aproximación los libros de tipo memorialístico escritos por mujeres sefardíes originarias del norte de África, que han sido igualmente prolíficas que las de la zona turco-balcánica a la hora de escribir y describir 
sus propias vivencias ( $\mathrm{p}$ 319). Para lo cual recurre a nueve textos dispares entre sí, Parte señalando que siempre ha existido literatura femenina pero que, debido al lugar que ocupaban las mujeres en la sociedad les fue más difícil ser reconocidas como escritoras. El resultado de su estudio demuestra que hay paralelismos entre la producción literaria turco balcánicas y las norteafricanas en las temáticas abordadas

\section{Parte. Un texto inédito de Laura Papo. "Bohoreta"}

Eliezer Papo, Avia de ser, escena de la vida de un tiempo con romansas, de Laura Papo “bohoreta” edision sientifika, anotada i komentada. El autor nos presenta una edición crítica de la obra de teatro escrita por Laura Papo en el idioma original, judeoespañol, con pie de página en donde va señalando el significado de aquellos términos difíciles de entender para el lector. Papo señala que tres temas principales okupavan la mente de esta mujer eksepsionala: el status de la mujer en la sosiedad sefaradí moderna, la revitalizasion dezeada de la lengua sefaradí i la prezervasion del riko folklor etniko del grupo..(p 340)

En definitiva, esta publicación monográfica está dedicada exclusivamente a la actividad de mujeres sefardíes como lectoras y escritoras. Los artículos han sido escritos por especialistas en cultura sefardí y constituyen un valioso aporte al conocimiento de la temática. 